\title{
Effects of cerebral oedema and arterial hypotension on cerebral blood flow in an animal model of hepatic failure
}

\author{
P. N. TREWBY, M. A. HANID, R. L. MACKENZIE 1, P. J. MELLON, AND \\ ROGER WILLIAMS
}

From the Liver Unit, King's College Hospital and Medical School, Denmark Hill, London

SUMMARY The effects of arterial hypotension and a raised intracranial pressure on cerebral blood flow (CBF) have been investigated in an animal model of hepatic failure. Arterial hypotension was associated with a fall in CBF in the animals with liver failure but not in the controls. Significant differences in mean $\mathrm{CBF}$ between the two groups of animals could be demonstrated when the systolic blood pressure was in the $30-60,60-90$, and $90-120 \mathrm{mmHg}$ range, but not in the $120-150$ $\mathrm{mmHg}$ range. A raised intracranial pressure also resulted in a fall in CBF in the animals with liver failure, and a significant difference could be demonstrated between the two groups when the intracranial pressure was in the $20-40 \mathrm{mmHg}$ range but not in the $0-20 \mathrm{mmHg}$ range. Furthermore, in the animals with liver failure the cerebral metabolic rate for oxygen $\left(\mathrm{CMRO}_{2}\right)$ fell as the $\mathrm{CBF}$ fell, there being a highly significant correlation between these two parameters. In the controls no such relation existed. Treatment with neither charcoal haemoperfusion nor high dose corticosteroids affected the fall in cerebral blood flow that occurred during arterial hypotension in the animals with liver failure. Corticosteroids, however, did reduce the fall in cerebral blood flow associated with a high intracranial pressure. These results suggest a disruption of the cerebral circulatory responses in hepatic failure. They also raise the possibility that $\mathrm{CMRO}_{2}$ and cerebral blood flow may be maintained at normal levels in hepatic encephalopathy if cerebral oedema and arterial hypotension can be prevented.

In healthy subjects cerebral autoregulation can maintain cerebral blood flow and cerebral metabolic rate constant over a wide range of blood pressure (Harper, 1965), but the competence of such autoregulation in patients with hepatic encephalopathy is uncertain. In both fulminant hepatic failure and chronic liver disease hypotension may occur spontaneously or after precipitating events, such as haemorrhage (Ward et al., 1977). Thus, in a recent study in fulminant hepatic failure (Trewby and Williams, 1977), we found that hypotension occurred in $88 \%$ of patients during their illness and $16 \%$ of their total time in grade IV coma (Trey and Davidson, 1970) was passed with a systolic blood pressure of less than $80 \mathrm{mmHg}$. Furthermore, cerebral oedema has been described in $38 \%$ of such cases examined at necropsy (Gazzard

\footnotetext{
1Present address: Department of Surgery, The Wellesley Hospital, Toronto, Ontario, Canada.

Received for publication 26 May 1978
}

et al., 1975), and the combination of a raised intracranial pressure with arterial hypotension would certainly be expected to reduce both cerebral blood flow (CBF) and cerebral oxygen delivery and result in a further deterioration in encephalopathy. In this study, we have investigated, in an animal model of hepatic failure, the effects of a raised intracranial pressure as well as a low systolic blood pressure on both CBF and cerebral metabolic rate for oxygen $\left(\mathrm{CMRO}_{2}\right)$. The effects of high dose corticosteroids given to prevent cerebral oedema, and charcoal haemoperfusion (Gazzard et al., 1974) used as a method of artificial liver support, on these cerebral circulatory responses have also been investigated.

\section{Methods}

The experiments were performed on 18 6-week-old Yorkshire Large White pigs $(18-20 \mathrm{~kg})$, in 13 of whom liver failure was induced. The remaining five served as controls. Both groups of animals were 
anaesthetised with intravenous thiopentone (12 $\mathrm{mg} / \mathrm{kg}$ ), and after intubation were placed on a volume cycled ventilator and maintained on halothane, nitrous oxide, and oxygen. Intravenous and intraarterial lines were established using the common femoral vessels. Antibiotics (streptomycin, 50 $\mathrm{mg} / \mathrm{kg}$; penicillin $\mathrm{G}$ sodium, $30 \mathrm{mg} / \mathrm{kg} ;$ and lincomycin, $30 \mathrm{mg} / \mathrm{kg}$ ) were given intravenously during the operation to prevent anaerobic septicaemia. In the test animals total devascularisation of the liver was carried out according to the technique first described by Rappaport et al. (1953) and developed by Opolon et al. (1971). The triangular ligaments of the liver, the hepatic arteries, and the common bile duct were divided, skeletonising the portal vein and the supra- and infra-hepatic portions of the inferior vena cava. A side-to-side portocaval shunt was then carried out, and the portion of the portal vein between the anastomosis and the liver was then doubly ligated and divided. In the control animals a laparotomy was performed and the hepatic artery and portal vein dissected but neither hepatic artery ligation nor portocaval shunt was carried out. During the operation the systolic blood pressure was maintained above $80 \mathrm{mmHg}$ by volume expansion where necessary.

In both groups of animals an intracranial (Gaeltec) pressure transducer was inserted into the subdural space through a burr hole over the parietal area. Finally, two catheters were introduced, one through a branch of the external jugular vein and the other through a branch of the external carotid artery, and their tips advanced so as to lie just within the internal carotid artery and internal jugular vein. The position of these catheters was confirmed by injecting methylene blue into the carotid catheter, when, if correctly placed, only the most lateral part of the eye turned blue and dye could be aspirated from the internal jugular catheter.

After the operation the animals were allowed to recover consciousness and breathe spontaneously. Subsequently, as signs of liver failure became apparent, inhalation of anaesthesia (nitrous oxide), and respiratory support with the ventilator were used to maintain the $\mathrm{paO}_{2}$ between 20 and $40 \mathrm{kPa}$ (mean $27.6 \pm 1 \mathrm{SEM} 1 \mathrm{kPa}$ in the controls and $37 \cdot 2 \pm 1$ SEM $6 \mathrm{kPa}$ in the test animals) and the paCO 2 between 4.5 and $6.0 \mathrm{kPa}$ (mean $5.5 \pm 1$ SEM $0.7 \mathrm{kPa}$ in the controls and $4.5 \pm 0.7 \mathrm{kPa}$ in the test animals). All animals received infusions of $10 \%$ dextrose $(500 \mathrm{ml} / 6 \mathrm{~h})$. Plasma glucose concentrations were measured using Dextrostix at four hourly intervals, and the levels were maintained at higher than $5.5 \mathrm{mmol}$. If the animals became very restless, they were sedated with $25 \mathrm{mg}$ doses of thiopentone. A five lead electroencephalogram was recorded at 30 minute intervals.

Biochemical evidence of liver failure in the test animals included the finding of a rise in plasma bilirubin and aspartate transaminase and a progressive slowing in the dominant frequency of the electroencephalogram. In all animals in the liver failure group a significant increase in blood ammonia had occurred within two hours of laparotomy (Hanid et al., 1978), and post-mortem histological examinations of the liver showed the presence of massive necrosis in the test animals but not in the controls.

In both groups of animals systolic blood pressure and intracranial pressure were monitored continuously. Systolic rather than mean blood pressure was chosen as the marker of arterial blood pressure, since, in the animals, as in man, this correlated better with the clinical state and with the EEG appearances.

Animals were killed at 12 hours after hepatic artery ligation, or when the electroencephalogram had been isoelectric for 30 minutes, whichever was the sooner.

\section{TREATMENT SCHEDULES}

In six of the 13 animals with liver failure, charcoal haemoperfusion was carried out starting four hours after hepatic artery ligation. In these animals a Scribner arteriovenous shunt was inserted between the femoral artery and femoral vein and whole blood was perfused through a column containing $100 \mathrm{~g}$ activated charcoal (Becton Dickinson Ltd), at a flow rate of $100-200 \mathrm{ml} / \mathrm{min}$, using a WatsonMarlow roller pump and standard dialysis lines, for a period of four hours. The animals were heparinised throughout the procedure to maintain a Lee-White whole blood clotting time of 10-20 minutes. Another five of the pigs were given methylprednisolone, the regimen consisting of a loading dose of $2 \mathrm{~g}$ followed by $500 \mathrm{mg}$ every two hours starting four hours after hepatic artery ligation. The remaining two pigs with liver failure received no specific treatment.

\section{MEASUREMENT OF CEREBRAL BLOOD FLOW} AND CMRO2

In the 13 pigs with liver failure, cerebral blood flow was measured at hourly intervals starting two hours after hepatic artery ligation, at a time when they had received neither charcoal haemoperfusion nor corticosteroids. In five of these animals, flow measurements were obtained when the systolic blood pressure was less than $90 \mathrm{mmHg}$. In four of these hypotension had occurred spontaneously, in one it was induced by haemorrhage. Measurements of cerebral blood flow were continued in those ani- 
mals treated with charcoal haemoperfusion or corticosteroids. Of these 11 animals, nine developed systolic blood pressures of less than $90 \mathrm{mmHg}$, seven spontaneously and two after haemorrhage. Hourly measurements of cerebral blood flow were also made in the five control animals, four of whom became hypotensive, two spontaneously, and two after haemorrhage. Standard techniques were used for measuring cerebral blood flow (Hoedt-Rasmussen and Veall, 1971). $0.5 \mathrm{mCi}$ of ${ }^{133} \mathrm{Xe}$ were injected into the internal carotid artery and the clearance from the brain monitored with a 3-in collimator, ratemeter, and recorder. The half life of ${ }^{133} \mathrm{Xe}$ in

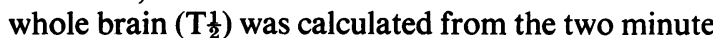
disappearance curve (Hoedt-Rasmussen and Veall, 1971), and the blood/whole brain xenon partition coefficient $(\lambda \mathrm{t})$ was corrected for haematocrit and assumed to have the same value as reported for human brain by Veall and Mallett (1965). Cerebral blood flow was calculated from the equation:

$\mathrm{CBF}(\mathrm{ml} / 100 \mathrm{~g} / \mathrm{min})=100 \times \lambda \mathrm{t} \times 0.693 / \mathrm{T} \frac{1}{2}$

The $\mathrm{CMRO}_{2}$ was determined in four of the control animals and in seven of the animals with liver failure from the product of $\mathrm{CBF}$ and the cerebral arteriovenous oxygen content difference. The latter was derived from the arterial and cerebral venous blood gas concentrations (measured using Radiometer electrodes), and the percentage haemoglobin saturation which was derived from the pig oxyhaemoglobin dissociation curves (Bartels and Harms, 1959).

\section{Results}

The progressive rise in intracranial pressure that occurred with the development of liver failure in this pig model has been previously described by Hanid et al. $(1976,1978)$. In the present group of animals the mean intracranial pressure was significantly greater within two hours of laparotomy than in the control animals, and thereafter it continued to rise until the animals' death. This rise in intracranial pressure was not significantly affected by charcoal haemoperfusion or corticosteroids when started four hours after hepatic artery ligation. On opening the calvaria at necropsy, all animals with liver failure had obviously swollen and oedematous brains with flattened cortical gyri, but no evidence of intracranial haemorrhage. In the control animals there was no post-mortem evidence of cerebral oedema, and in only one of the five controls did the intracranial pressure rise above $40 \mathrm{mmHg}$ and this was shortly before death, the animal having sustained a subdural haematoma.

Although in the individual animals with liver failure there was no correlation between arterial blood pressure and cerebral blood flow, taking the group as a whole a highly significant correlation could be demonstrated between these two parameters $(r=0.52, \mathrm{P}<0.001)$. In the control animals no such relation could be demonstrated $(r=0 \cdot 11$, $P$ NS). Because the difference between the two groups could be due to the higher intracranial pressure in the animals with liver failure, a separate analysis was carried out of the relation between blood pressure and cerebral blood flow in those animals with liver failure whose intracranial pressure was less than $25 \mathrm{mmHg}$. A significant correlation was still found between the two parameters $(r=0.48, \mathrm{P}<0.05)$.

To facilitate further statistical comparison between the animals with liver failure and the controls the values for cerebral blood flow were divided according to whether the systolic blood pressure lay between $30-60,60-90,90-120$, or $120-150 \mathrm{mmHg}$ (Fig. 1). In the three lower blood pressure ranges $(30-60,60-90$, and $90-120 \mathrm{mmHg})$ the mean cerebral

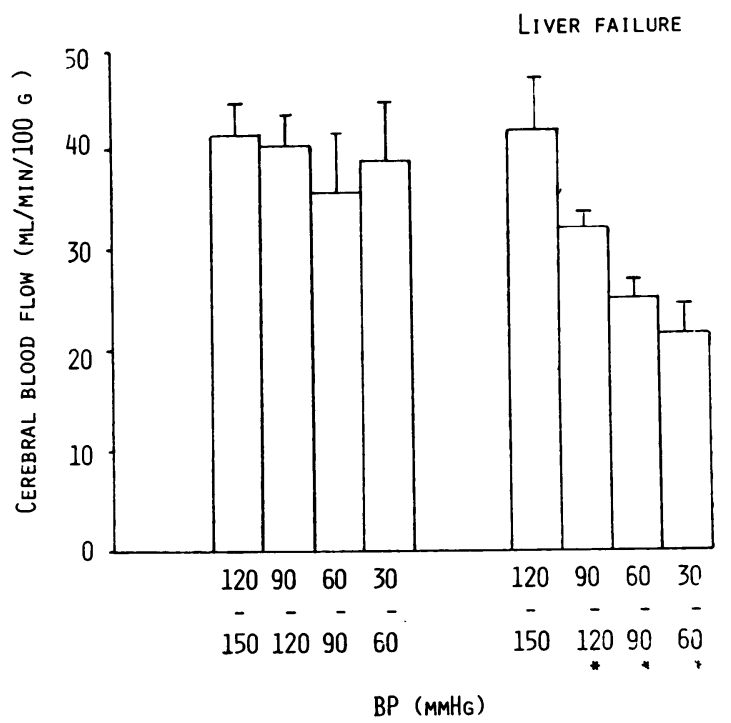

Fig. 1 Cerebral blood flow (mean $\pm 1 S E M$ ) in different blood pressure ranges in the control animals and the animals with liver failure. * Significant difference in mean cerebral blood flow compared to controls.

blood flow was significantly lower in the animals with liver failure than in the controls $(P<0.02$, $P<0.01, P<0.005$ respectively for each difference, Fig. 1). In the $120-150 \mathrm{mmHg}$ range there was no difference in mean cerebral blood flow between the two groups of animals. In the animals with liver failure, but not in the controls, values for mean cerebral blood flow were significantly lower in the 
90-120 $\mathrm{mmHg}$ blood pressure range than in the $120-150 \mathrm{mmHg}$ range $(\mathrm{P}<0.01$, Fig. 1$)$ and also significantly lower in the $60-90 \mathrm{mmHg}$ range than in the $90-120 \mathrm{mmHg}$ range $(\mathrm{P}<0.05)$. Raised intracranial pressure could not account for these differences in cerebral blood flow for there was no significant difference in mean intracranial pressure in the four blood pressure ranges.

When the effects of a raised intracranial pressure on cerebral blood flow were analysed a significant correlation was found between these two parameters in the animals with liver failure taken as a whole $(r=-0.32, \quad \mathrm{P}<0.01)$, those animals with the highest intracranial pressure having the lowest cerebral blood flow. A similar but statistically less significant correlation could also be demonstrated in the control animals $(r=-0.35, \quad \mathrm{P}<0.05)$. When only those observations associated with a systolic blood pressure of more than $90 \mathrm{mmHg}$ were considered, a significant correlation was still found between intracranial pressure and cerebral blood flow in the animals with liver failure $(r=-0.44$, $P<0.01$ ), but no such relation was found in the control animals $(r=-0 \cdot 22$, P NS). When the values for cerebral blood flow were divided into groups according to the level of intracranial pressure, the mean cerebral blood flow was found to be significantly lower in the animals with liver failure than in the controls when the intracranial pressure was in the $20-40 \mathrm{mmHg}$ range, but in the $0-20 \mathrm{mmHg}$ range there was no difference between the two groups (Fig. 2).

When the combined influence of arterial hypotension and a raised intracranial pressure on cerebral blood flow was analysed using three variable linear regressions, a highly significant correlation was found between cerebral blood flow and the combination of blood pressure and intracranial pressure in the animals with liver failure (line of best fit $\mathrm{CBF}=0.143 \times \mathrm{BP}-0.214 \times \mathrm{ICP}+21 \cdot 2, r=0.67$, $P<0.001)$. No such correlation could be demonstrated in the control animals (line of best fit: $\mathrm{CBF}=0.22 \times \mathrm{BP}-0.19 \times \mathrm{ICP}+29.3, r=0.34$, $P$ NS), and in neither group of animals was any relation found between blood pressure and intracranial pressure.

\section{EFFECT OF CHARCOAL HAEMOPERFUSION}

\section{AND CORTICOSTEROIDS}

Neither charcoal haemoperfusion nor corticosteroids had any effect on the reduction in cerebral blood flow that occurred at low blood pressures, the mean cerebral blood flow in the blood pressure range $120-150 \mathrm{mmHg}, 90-120 \mathrm{mmHg}$, and $60-90 \mathrm{mmHg}$ not differing significantly from those found in the animals with liver failure before treatment (Table 1).

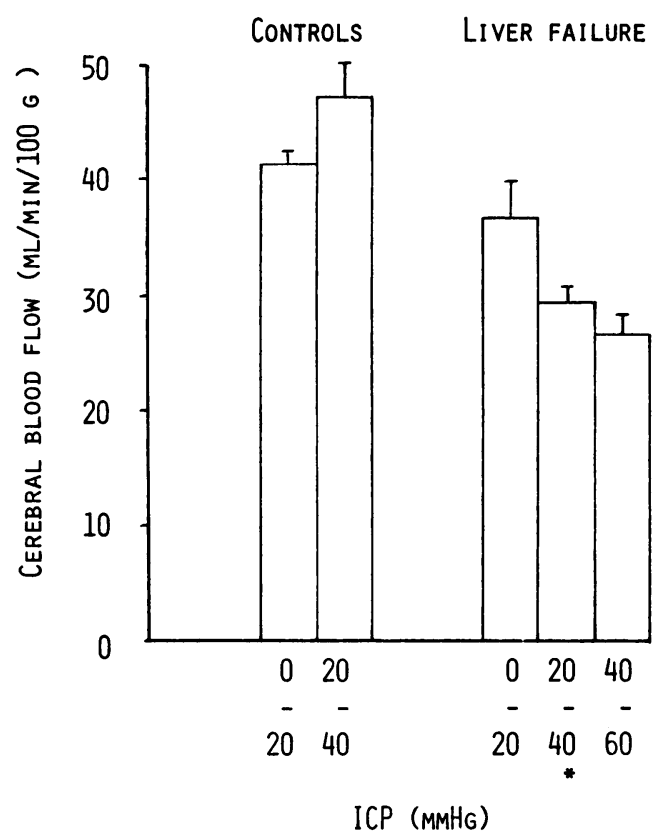

Fig. 2 Cerebral blood flow (mean \pm 1 SEM) in different intracranial pressure ranges in the control animals with liver failure. * Significant difference in mean cerebral blood flow compared to controls. All observations taken when systolic $\mathrm{BP}>90 \mathrm{mmHg}$.

Table 1 Mean cerebral blood flow $(\mathrm{ml} / \mathrm{min} / 100 \mathrm{~g})$ \pm 1 SEM in different blood pressure ranges in controls and in treated and untreated animals with liver failure

\begin{tabular}{|c|c|c|c|c|}
\hline $\begin{array}{l}\text { Blood pressure } \\
(\mathrm{mmHg})\end{array}$ & $120-150$ & $90-120$ & $60-90$ & $30-60$ \\
\hline $\begin{array}{l}\text { Controls } \\
\text { Liver failure } \\
\text { before treatment }\end{array}$ & $\begin{array}{l}41 \cdot 5 \pm 28 \\
34 \cdot 8 \pm 7 \cdot 1\end{array}$ & $\begin{array}{l}40.4 \pm 2.5 \\
28.7 \pm 2.7\end{array}$ & $\begin{array}{l}35 \cdot 1 \pm 5.8 \\
19.5 \pm 1 \cdot 1\end{array}$ & $\begin{array}{l}37 \cdot 6 \pm 7 \cdot 1 \\
13 \cdot 8 *\end{array}$ \\
\hline $\begin{array}{l}\text { Charcoal } \\
\text { haemoperfusion }\end{array}$ & $75 \cdot 6^{*}$ & $31 \cdot 3 \pm 3 \cdot 3$ & $25 \cdot 7 \pm 2 \cdot 1$ & $23 \cdot 3 \pm 2 \cdot 6$ \\
\hline Corticosteroids & $35.4 \pm 2.6$ & $30.4 \pm 2.0$ & $24.9 \pm 2 \cdot 2$ & 一 \\
\hline
\end{tabular}

*Mean of two observations only.

When divided according to treatment regime, significant correlations were found between systolic blood pressure and cerebral blood flow in the animals treated by charcoal haemoperfusion $(r=0.58$, $P<0.001$ ), and in the animals treated with corticosteroids $(r=0.72, \quad \mathrm{P}<0.001)$ and also in the animals before the start of either charcoal haemoperfusion or corticosteroids $(r=0.60, \mathrm{P}<0.01)$.

Similarly, charcoal haemoperfusion had no effect on the reduction in cerebral blood flow that occurred at high intracranial pressures, the mean cerebral blood flow in the $0-20,20-40$, and $40-60 \mathrm{mmHg}$ range not differing significantly from those found in the 
animals before treatment.

In those animals treated with corticosteroids, however, the mean cerebral blood flow was not so reduced in the $40-60 \mathrm{mmHg}$ intracranial pressure range as in the untreated animals or the animals treated with charcoal haemoperfusion (Table 2).

Table 2 Mean cerebral blood flow ( $\mathrm{ml} / 100 \mathrm{~g} / \mathrm{min}$ ) \pm 1 SEM separated into three groups according to intracranial pressure in control animals and in treated and untreated animals with liver failure

\begin{tabular}{llll}
\hline Intracranial pressure $(\mathrm{mmHg})$ & $0-20$ & $20-40$ & $40-60$ \\
\hline Controls & $40.4 \pm 1.5$ & $41 \cdot 1 \pm 3.4$ & $1.4 *$ \\
Liver failure before treatment & $36.4 \pm 3.0$ & $25.2 \pm 3.4$ & $26.3 \pm 1 \cdot 1$ \\
Charcoal haemoperfusion & $27.2 \pm 1.7 \pm$ & $23.7 \pm 2.9$ & $22.4 \pm 1.2$ \\
Corticosteroids & - & $31.5 \pm 2.9$ & $29.9 \pm 1.3 \dagger$ \\
\hline
\end{tabular}

* Mean of two observations only; †cerebral blood flow significantly higher $(P<0.001)$ than in the untreated animals with liver failure; fblood pressure significantly lower in this group than in control group so cerebral blood flow cannot be compared.

A significant correlation was also found using three variable linear regressions between cerebral blood flow and the combination of blood pressure and intracranial pressure in animals before treatment $(\mathrm{CBF}=0.23 \times \mathrm{BP}-0.37 \times \mathrm{ICP}+9.4, r=0.80$,
$P<0.001$ ), in animals after treatment with charcoal haemoperfusion $(\mathrm{CBF}=0.086 \times \mathrm{BP}-0.15 \times \mathrm{ICP}+$ $16.5, r=0.53, \mathrm{P}<0.01)$ and in animals after treatment with corticosteroids $(\mathrm{CBF}=\mathbf{0 . 1 4} \times \mathrm{BP}-$ $0.087 \times \mathrm{ICP}+16.6, r=0.66, \mathrm{P}<0.001)$.

\section{RELATION BETWEEN CEREBRAL BLOOD FLOW} AND $\mathrm{CMRO}_{2}$

Analysis of the relation between cerebral blood flow and $\mathrm{CMRO}_{2}$ showed a significant correlation in the animals with liver failure (Fig. 3). No such correlation was seen in the control animals, in whom the cerebral A-V $\mathrm{O}_{2}$ content difference increased as the cerebral blood flow fell, so tending to maintain the $\mathrm{CMRO}_{2}$ constant despite low cerebral blood flows (Fig. 3). At low cerebral blood flows (less than $37.5 \mathrm{ml} / \mathrm{min} / 100 \mathrm{~g}$ ) the mean $\mathrm{CMRO}_{2}$ was significantly lower in the animals with liver failure than in controls with values of $1.03 \pm 0.10$ and $1.82 \pm 0.20 \mathrm{ml} / \mathrm{min} / 100 \mathrm{~g}$ respectively (mean \pm 1 SEM, $P<0.01$ ). When the cerebral blood flow was greater than $37.5 \mathrm{ml} / \mathrm{min} / 100 \mathrm{~g}$, however, there was no significant difference between the two groups, with values respectively of $1.60 \pm 0.25$ and $1.33 \pm$ $0.15 \mathrm{ml} / \mathrm{min} / 100 \mathrm{~g}$ (mean $\pm 1 \mathrm{SEM}, \mathrm{P}$ NS). Numbers were not sufficient to allow separate analysis of the

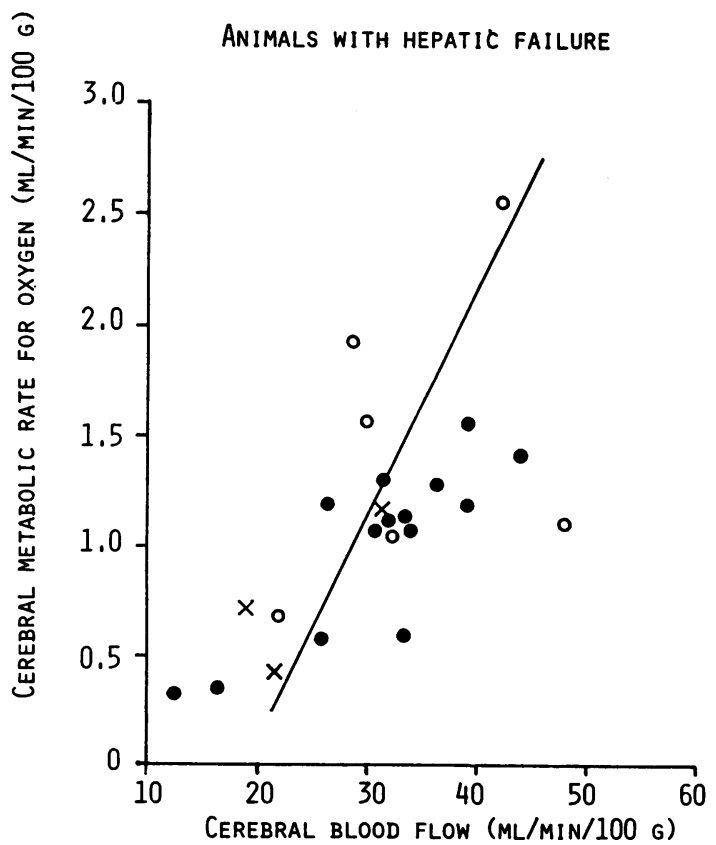

Fig. 3 Showing a significant correlation between cerebral blood flow and $\mathrm{CMRO}_{2}$ in animals with liver failure $(\mathrm{r}=0.58, \mathrm{P}<0.01)$ but not in controls $(\mathrm{r}=-0.062, \mathrm{P} N S) X$ : untreated animals, $\bigcirc:$ measurement made during treatment with charcoal haemoperfusion, $\bigcirc$ : measurement made during treatment with corticosteroids. 
effect of the high dose corticosteroids or charcoal haemoperfusion on $\mathrm{CMRO}_{2}$ in the animals with liver failure.

\section{Discussion}

These studies suggest that, in this animal model of liver failure, there is a marked derangement of cerebral autoregulation in response to both a low systolic blood pressure and a rise in intracranial pressure. Although the use of the two minute disappearance curve of ${ }^{133} \mathrm{Xe}$ for measuring cerebral blood flow may not give as accurate a measure of absolute flow as analysis of the 10 or 15 minute curves (Van Duyl et al., 1976), it is a method which has been extensively used in man and other primates (Hoedt-Rasmussen and Veall, 1971), and was chosen in this series of experiments because of its usefulness for assessing rapidly changing flow in an unstable clinical situation. Inaccuracies due to extracerebral contamination with ${ }^{133} \mathrm{Xe}$ are unlikely to be significant because injection of methylene blue into the arterial cannula resulted in virtually no extracerebral staining. The advantage of this method over alternative methods for measuring rapidly changing cerebral blood flow, such as the use of electromagnetic flowmeters, is that an extensive dissection of the carotid artery is not necessary, so the accompanying vasomotor nerve fibres, some of which may be important in regulating cerebral blood flow, remain undisturbed.

In the control animals, despite heavy sedation and a recent general anaesthetic, cerebral blood flow was maintained when hypotension occurred. The reduction in cerebral blood flow that occurred in the hypotensive animals with liver failure could not be accounted for on the basis of hypoxaemia or hypercapnia, for the $\mathrm{paCO}_{2}$ was maintained within narrow limits and the oxygen tension was greater than $100 \mathrm{mmHg}$. Nor could it be explained on the basis of a higher intracranial pressure in the hypotensive than in the normotensive animals. Likewise the significant fall in cerebral blood flow that occurred when intracranial pressure rose to high levels in the animals with liver failure could not be accounted for on the basis of arterial hypotension.

Combined analysis of the effect of intracranial pressure and blood pressure on cerebral blood flow showed a significant correlation between these parameters in the animals with liver failure, but not in the controls. A further distinction between the two groups of animals was the failure of cerebral oxygen extraction to increase at low cerebral blood flows in the animals with liver failure, this resulting in a decrease in $\mathrm{CMRO}_{2}$. One explanation for this would be the opening up of intracerebral arteriovenous shunts (Rowed et al., 1972). Such shunts have been described in the systemic (Tyor and Sieker, 1959) and pulmonary circulation (Robin et al., 1975) in both acute and chronic liver failure. At low flow rates the shunting of blood through such low resistance vessels in the brain would result in tissue hypoxia and a diminished $\mathrm{CMRO}_{2}$ despite a high arterial and cerebral venous oxygen content. An alternative explanation is that cellular respiration in the animals with liver failure might be more sensitive to the build-up of metabolites that would accompany a low cerebral blood flow. The subsequent reduction in intracellular $\mathrm{pH}$ might be sufficient to lower the $\mathrm{CMRO}_{2}$, especially if combined with a pre-existing intracellular acidosis. The latter is well described in patients with liver disease even in the presence of an extracellular alkalosis (Bittar et al., 1962).

In this series of experiments rather low values for cerebral blood flow and $\mathrm{CMRO}_{2}$ were found, even in the normotensive controls. However, similar low values have been reported by Van Duyl et al. (1976) using ${ }^{133} \mathrm{Xe}$ to measure cerebral blood flow in the pig. In our calculation of $\mathrm{CMRO}_{2}$, however, an extracerebral component to the oxygen content of the blood in the internal jugular vein could result in a spuriously low value for $\mathrm{CMRO}_{2}$ being obtained. Also the derivation of blood oxygen content from the oxygen tension may result in inaccuracies in the calculated $\mathrm{CMRO}_{2}$ if the oxy-haemoglobin dissociation curve were shifted in hepatic failure. However, previous workers have shown that, if a shift does occur, it is a shift to the right (Fritts, 1963), which would have the effect of increasing rather than decreasing the calculated $\mathrm{CMRO}_{2}$.

Another study carried out in a goat model of hepatic failure on cerebral circulatory responses has shown a marked reduction in the normal cerebral vasodilatation that occurs in response to hypoxaemia (Stanley and Cherniack, 1976) or hypercapnia (Stanley et al., 1975). When taken together with our findings, these studies suggest a failure of many aspects of cerebral homeostatic mechanisms in hepatic failure. Underlying these changes may be the accumulation of toxic intermediates influencing both the neuronal and humoral mechanisms which are thought to be involved in cerebral autoregulation (Harper et al., 1972). The lack of improvement with charcoal haemoperfusion does not exclude a toxic aetiology, for irreversible brain damage might have occurred before it is started. Alternatively, the putative compounds may be ineffectually removed by activated charcoal.

In the present study, corticosteroids given four hours after hepatic artery ligation had no effect 
on the low cerebral blood flow that occurred in the animals with liver failure when hypotensive. They did, however, lessen the fall in cerebral blood flow that occurred at high levels of intracranial pressure. The mechanism and clinical significance of this is not clear, for in man high dose corticosteroids given at the onset of coma have affected neither the incidence of cerebral oedema nor the overall survival (Gazzard et al., 1975), and this would be consistent with the observations of Hanid et al. (1976) that, in this animal model, high doses of steroids need to be given immediately after hepatic artery ligation if a raised intracranial pressure is to be avoided. The lack of an effective method of treating or preventing cerebral oedema in patients with hepatic failure makes it all the more important to prevent episodes of hypotension if secondary hypoxic brain damage is to be avoided. Of particular importance in this respect are the prevention of gastrointestinal bleeding, the avoidance of hypovolaemia, and the prompt treatment of cardiac arrhythmias, blood gas and electrolyte disturbances, all of which, by resulting in arterial hypotension, may reduce both cerebral blood flow and $\mathrm{CMRO}_{2}$.

Martin Clarke and Pyra Majumdar provided assistance with the isotope studies. We are also grateful to the Medical Research Council and Smith \& Nephew Research Ltd for their support, and to Linda Rimmer for editorial assistance. R. L. Mackenzie was supported by a Roscoe Reid Graham Travelling Fellowship of the University of Toronto.

\section{References}

Bartels, H., and Harms, H. (1959). Sauerstoffdissaziationskurven des Blutes von Säugetieren. Pflugers Archiv für die Gesamte Physiologie des Menschen und der Tiere, 268, 334-365.

Bittar, E. E., Watt, M. F., Pateras, V. R., and Parrish, A. E. (1962). The pH of muscle in Laennec's cirrhosis and uremia. Clinical Science, 23, 265-276.

Fritts, H. W. (1963). Systemic circulatory adjustments in hepatic disease. Medical Clinics of North America, 47, 563-578.

Gazzard, B. G., Portmann, B., Murray-Lyon, I. M., and Williams, R. (1975). Causes of death in fulminant hepatic failure and relationship to quantitative histological assessment of parenchymal damage. Quarterly Journal of Medicine, 44, 615-626.

Gazzard, B. G., Weston, M. J., Murray-Lyon, I. M., Flax, H., Record, C. O., Portmann, B., Langley, P. G., Dunlop, E. H., Mellon, P. J., Ward, M. B., and Williams, R. (1974). Charcoal haemoperfusion in the treatment of fulminant hepatic failure. Lancet, 1, 1301-1307.
Hanid, M. A., Mackenzie, R. L., Jenner, R. E., Chase, R. A., Mellon, P. J., Trewby, P. N., Janota, I., Davis, M., Silk, D. B. A., and Williams, R. (1978). Intracranial pressure in pigs with surgically induced acute liver failure. Gastroenterology, in press.

Hanid, M. A., Mackenzie, R. L., Mellon, P. J., and Williams, R. (1976). Experimental production of cerebral oedema in an animal model of fulminant hepatic failure and effects of various treatment measures (Abstract). Digestion, 14, 517.

Harper, A. M. (1965). Physiology of cerebral bloodflow. British Journal of Anaesthesia, 37, 225-235.

Harper, A. M., Deshmukh, V. D., Rowan, J. O., and Jennett, W. B. (1972). The influence of sympathetic nervous activity on cerebral blood flow. Archives of Neurology, 27, 1-6.

Hoedt-Rasmussen, K., and Veall, N. (1971). Studies of cerebral blood flow. In Radioisotopes in Medical Diagnosis, p. 508. Edited by E. H. Belcher and H. Vetter. Butterworths: London.

Opolon, P., Huguet, C., Hadchouel, P., Morisot, P., Bloch, P., Gallot, D., Duhurt, J., Connard, J., Sausse, A., Stern, A., Granger, A., and Caroli, J. (1971). Coma hépatique expérimental par nécrose ischémique aiguë du foie chez le porc. Tentatives de prévention et de traitement par hémodialyse croisée. Annales de Medicine Internale (Paris), 122, 819-832.

Rappaport, A. M., MacDonald, M. H., and Borowy, Z. J. (1953). Hepatic coma following ischaemia of the liver. Surgery, Gynecology, and Obstetrics, 97, 748-768.

Robin, E. D., Horn, B., Goris, M. L., Theodore, J., Kessel, A. van, Mazoub, J., and Tilkian, A. (1975). Detection, quantitation and pathophysiology of lung 'spiders'. Transactions of the Association of American Physicians, 88, 202-217.

Rowed, D. W., Stark, V. J., Hoffer, P. B., and Mullan, S. (1972). Cerebral arteriovenous shunts re-examined. Stroke, 3, 592-600.

Stanley, N. N., and Cherniack, N. S. (1976). Effect of liver failure on the cerebral circulatory and metabolic responses to hypoxia in the goat. Clinical Science and Molecular Medicine, 50, 15-23.

Stanley, N. N., Salisbury, B. G., McHenry, L. C., Jr., and Cherniack, N. S. (1975). Effect of liver failure on the response of ventilation and cerebral circulation to carbon dioxide in man and in the goat. Clinical Science and Molecular Medicine, 49, 157-169.

Trewby, P. N., and Williams, R. (1977). The pathophysiology of hypotension in patients with fulminant hepatic failure. Gut, 18, 1021-1026.

Trey, C., and Davidson, C. S. (1970). The management of fulminant hepatic failure. In Progress in Liver Disease, vol 3, pp. 282-298. Edited by H. Popper and F. Schaffner. Grune and Stratton: New York.

Tyor, M. P., and Sieker, H. O. (1959). Biochemical, blood gas and peripheral circulatory alterations in hepatic coma. American Journal of Medicine, 27, 50-59.

Van Duyl, W. A., Sparreboom, D., and Volkers, A. C. W. (1976). Compartmental models of cerebral blood flow. Analysis using the $81-\mathrm{keV}$ and $31-\mathrm{keV}$ photons of ${ }^{133} \mathrm{Xe}$. Journal of Nuclear Medicine, 17, 596-602.

Veall, N., and Mallett, B. L. (1965). The partition of trace amounts of Xenon between human blood and brain tissues at $37^{\circ} \mathrm{C}$. Physics in Medicine and Biology, 10, 375-380.

Ward, M. E., Trewby, P. N., Williams, R., and Strunin, L. (1977). Acute liver failure: experience in a special unit. Anaesthesia, 32, 228-239. 